\title{
A Technical Information System for Range Mangement
}

\section{STAN TIXIER}

How many times have you as a practicing range manager (whether a researcher, public land administrator, range technician, or stockman) pondered the question, "How can I get my hands on published research findings to help me solve a specific problem?" Sure, you have a stack of Journal of Range Management, a bookcase full of various publications, and maybe a pretty good card filc, and the answer you're looking for may well be there. Maybe you're better organized for this task than most, but still, finding all of the pertinent material can be a frustrating, time-consuming experience. There has to be a better, quicker, more efficient way. There is! Or at least there soon will be. It is within reach in the state of the art, and being developed by the Society for Range Management, three cooperating Federal agencies, and Colorado State University.

Under an agreement recently signed by the Forest Service (in cooperation with the Soil Conservation Service and Bureau of Land Management) and Colorado State University, the first phase of input into a technical information system for range management is underway. Phase One includes all of the articles that have appeared in the Journal of Range Management since

Author is assistant director, range management, Forest Service, U.S. Department of Agriculture, Washington, D.C. 20250. it was first published in 1948. These articles are being cataloged, and pertinent information fed into an Energy Research and Development computer in Oak Ridge, Tennessee. In later phases, range articles in other publications will be added. These will include other journals, periodicals, publications, technical papers, and dissertations-the full scope of published scientific information on the subject of range management.

The system is designed to be kept current. Future articles of the Journal will be included automatically. Provisions will be made to add other scientific range information as it becomes available.

Once the computer based file is constructed, it will be made available to interested users through an information brokerage service. That may sound complicated, but what it means to you and me is this: If we want to know what has been published on a given subject, we simply define that subject as precisely as possible by using appropriate key words and standard range terminology (as appears in the new glossary for range terms). Then we call or write the information broker and request a printout of the pertinent information on that subject. We will pay a nominal fee for the service provided. If we have access to a subscribing terminal, we can get the information back in a matter of minutes; otherwise, it will require regular mail service time. 
A future refinement of this system will be availability of information digests or detailed abstracts of more recent or pertinent material. With this service, a great deal of information on a given subject can be obtained quickly and efficiently.

Such systems are currently available for a few other disciplines and being developed for several others. The range technical information system promises to be a tremendous assist to range managers in rapidly locating the material they need. Research on the shelf and gathering dust does little good. This system is designed to make a wide range of research findings readily available to those who can best put it to work with a minimum of time, effort, and expense. It should be a significant step forward in range management. 